\begin{tabular}{|c|c|c|}
\hline \multirow{3}{*}{$\begin{array}{r}\text { Case Reports in } \\
\text { Gastroenterology }\end{array}$} & \multirow{2}{*}{\multicolumn{2}{|c|}{ Case Rep Gastroenterol 2014;8:286-290 }} \\
\hline & & \\
\hline & $\begin{array}{l}\text { DOI: 10.1159/000368302 } \\
\text { Publisned online: Uctober 3, } 2014\end{array}$ & $\begin{array}{l}\text { (c) } 2014 \text { S. Karger AG, Basel } \\
\text { 1662-0631/14/0083-0286 } \$ 39.50 / 0 \\
\text { www.karger.com/crg }\end{array}$ \\
\hline & \multicolumn{2}{|c|}{$\begin{array}{l}\text { This is an Open Access article licensed under the terms of the Creative Commons } \\
\text { Attribution-NonCommercial } 3.0 \text { Unported license (CC BY-NC) (www.karger.com/OA } \\
\text { license), applicable to the online version of the article only. Distribution permitted for non } \\
\text { commercial purposes only. }\end{array}$} \\
\hline
\end{tabular}

\title{
Hepatogastric Fistula following Transcatheter Arterial Chemoembolization of Hepatocellular Carcinoma
}

\author{
Inderpreet Grover ${ }^{\mathrm{a}} \quad$ Naveed Ahmad $^{\mathrm{b}} \quad$ Amber B. Googe ${ }^{c}$ \\ ${ }^{a}$ Internal Medicine, G.V. (Sonny) Montgomery VA Medical Center, Jackson, Miss., \\ ${ }^{b}$ Department of Gastroenterology, Indiana University Health Arnett, Lafayette, Ind., and \\ 'University of Mississippi Medical Center, Jackson, Miss., USA
}

\section{Key Words}

Hepatogastric fistula - Transcatheter arterial chemoembolization · Hepatocellular carcinoma . Endoscopy

\begin{abstract}
Hepatogastric fistula (HGF) formation following transcatheter arterial chemoembolization (TACE) leads to increased morbidity and mortality. A 51-year-old Caucasian male with chronic hepatitis B virus-associated cirrhosis and unresectable hepatocellular carcinoma (HCC) presented to the Interventional Radiology Unit for TACE to achieve tumor necrosis. Following the procedure, the patient was admitted with symptoms of fever, epigastric and right upper quadrant pain secondary to the development of an abscess. The abscess was drained; however, an exceedingly rare HGF resulted that was favored to represent a direct invasion of HCC. HGF, the rare complication following TACE, leads to grave consequences and vigilant monitoring, for the development of this entity is recommended to reduce patient mortality. We present a case and literature review of HGF development following TACE for HCC.
\end{abstract}

(C) 2014 S. Karger AG, Basel

\section{Introduction}

Hepatocellular carcinoma (HCC) is the third leading cause of death from cancer worldwide and is the ninth leading cause of cancer-related deaths in the United States [1]. Hepatogastric fistula (HGF) development is a rare complication of transcatheter arterial 
Grover et al.: Hepatogastric Fistula following Transcatheter Arterial

Chemoembolization of Hepatocellular Carcinoma

chemoembolization (TACE) of the hepatic artery for HCC. TACE is performed as a palliative measure for unresectable malignant tumors to reduce pain and slow growth of the mass by producing vascular compromise leading to necrosis of the mass. Such tissue hypoxia can be destructive to normal tissue and can increase the tumor burden leading to metastatic disease [2]. An unfortunate complication of TACE is an abscess development that occurs in less than $1 \%$ of the cases [3]. It is hypothesized that the ischemic necrosis that follows the TACE procedure may partially be responsible for the occurrence of HGF [4]. The complications from this aberrant communication of visceral organs lead to rapid status decline and to patient opting for hospice care. We present a case and literature review of HGF following TACE, which was performed to provide palliative care for an unresectable hepatitis B virusrelated HCC tumor.

\section{Case Report}

A 51-year-old Caucasian male with chronic hepatitis B virus-associated cirrhosis and biopsy-proven HCC was treated with TACE for an unresectable malignant liver mass. At his initial presentation, the patient complained of right upper quadrant pain, a 20-lb unintentional weight loss (initial weight: $180 \mathrm{lbs}$, weight at presentation: $160 \mathrm{lbs}$ ), and an epigastric mass. Physical examination showed a cachectic-appearing male with jaundice and hepatomegaly. The laboratory results were significant for anemia of chronic disease, elevated liver enzymes with a total bilirubin of $2.2 \mathrm{mg} / \mathrm{dl}$, marked thrombocytopenia, and an elevated international normalized ratio of 1.72. The patient was Child Class B and had a Model for End-Stage Liver Disease (MELD) score of 21. An abdominal computed tomography (CT) scan showed a heterogeneous, hypervascular mass arising in the lateral segment of the lower left lobe of the liver (segments II and III) measuring $11.5 \times 9.5 \times 5.3 \mathrm{~cm}$ in size suggestive of HCC. His $\alpha$-fetoprotein levels were markedly elevated. General surgery was consulted and found the mass to be unresectable. Their recommendations included palliative measures with TACE and pain management. The patient subsequently underwent TACE of the hepatic mass, which later was complicated by a liver abscess. Out of concern for infectious etiology, the hepatic abscess was drained by interventional radiology.

Approximately 6 months following the first TACE, the patient presented for his second TACE. At that time, he reported a recent history of melena and coffee ground emesis, which were suggestive of an upper gastrointestinal hemorrhage. Unfortunately, the patient could not accurately correlate the symptoms in relation to the first TACE. A gastroenterology consultation was requested, and the team suspected a fistulous connection between the HCC mass and the stomach, which was seen on the abdominal CT (fig. 1). The patient underwent esophagogastroduodenoscopy that revealed a $2-\mathrm{cm}$ ulcer to the lesser curvature of the stomach communicating with the liver, forming a HGF (fig. 2). This ulcer and surrounding tissue were believed to represent recurrent HCC or metastatic HCC. Surgical consultation again recommended supportive care after considering the patient's advanced disease status and poor candidacy for surgical intervention. Gastroenterology recommended the use of proton pump inhibitors and the avoidance of nasogastric and orogastric tubes to prevent further complications while hospitalized. CT and esophagogastroduodenoscopy results along with poor prognosis secondary to the advanced disease were discussed with the patient, following which, the patient opted for hospice care. 
Grover et al.: Hepatogastric Fistula following Transcatheter Arterial

Chemoembolization of Hepatocellular Carcinoma

\section{Discussion}

Direct invasion of HCC to adjacent organs is one of the most common routes of metastasis along with hematogenous and lymphatic spread [4]. The most common site of direct tumor invasion is the stomach followed by the duodenum and colon [5]. Most metastases to the gastrointestinal tract (GIT) are found incidentally secondary to their asymptomatic presentation, but bleeding from the upper GIT is the most common initial presentation [6, 7]. HGF following TACE is an extremely rare complication of the procedure. Careful patient selection is a must for the TACE procedure. Risk factors for the development of HGF include liver cirrhosis, local or regional radiation, previous TACE of the liver or stomach, large lesions from HCC which are close to the GIT, and hepatic abscess. Indications for TACE include: confirmed diagnosis of HCC, absence of extrahepatic metastases, targeted tumor involving $50 \%$ or more of the liver parenchyma, disease recurrence after potentially curative treatment, and if ablation is unfeasible [8,9]. A further indication is given in a potential transplant recipient requiring bridge therapy to minimize the drop-off rate from the transplant list. Contraindications to TACE include: portal vein thrombosis, portal flow reversal, and Child Class C cirrhosis [10,11]. Contraindications to the chemotherapeutic agent and anaphylactic reactions to the contrast media also remain to be considered.

When considering TACE as a therapy option, the metabolic status of the candidate must be evaluated. Serum creatinine must be $\leq 2 \mathrm{mg} / \mathrm{dl}$, platelet count $\geq 50,000 / \mathrm{mm}^{3}$, and prothrombin activity $\geq 50 \%$ [12]. Few case reports of HGF following TACE exist, and the mechanism is not clearly understood, with even less literature available concerning treatment options. While there is no widely accepted pathophysiologic mechanism for HGF development, a review of the literature suggests that a direct invasion of HCC to the stomach is more likely to develop in patients with a history of loco-regional treatment such as TACE or intra-arterial chemotherapy $[13,14]$. As such, we can hypothesize that the direct tumor invasion might result from the adhesion of HCC after loco-regional treatment. TACE for HCC might induce an inflammatory reaction along with local tissue hypoxia in the proximity, which causes the serosal side of the stomach to become adherent to a tumor capsule [13, 15]. Park et al. [4] reported that the main factors for the direct invasion were growth pattern, tumor size, and location rather than a previous history of loco-regional treatment. In the case documented above, the patient was treated with repeated TACE, and there was a fistulous connection noted between the left lobe of the liver and the stomach following the procedure. All the factors discussed above and the abscess formation might have contributed to a direct gastric invasion by HCC and resulted in the formation of HGF.

Regardless of the etiology, this inappropriate communication between the stomach and the liver results in hepatogastric irritation and inflammation that leads to symptoms such as pain, hemorrhage, melena, and hematemesis. Closer surveillance is warranted in patients undergoing successive TACE or radiotherapy for HCC close to the GIT, as complications including fistula, abscesses, hemorrhage, and perforation can develop leading to devastating consequences. More studies are needed to indicate the potential benefits of routine surveillance with ultrasound or CT scan for an early detection of asymptomatic fistulas that represent disease metastasis. Quality of life and surgical risks should also be taken into consideration before undertaking additional procedures.

In conclusion, HGF secondary to an invasion by HCC is rare and should be included in the differential diagnosis of patients presenting with upper GIT bleed who have undergone TACE for advanced HCC.

Informed consent was obtained from the patient. 


\begin{tabular}{l|l}
\hline \multicolumn{2}{l}{ Case Rep Gastroenterol 2014;8:286-290 } \\
\hline DOI: $10.1159 / 000368302$ & $\begin{array}{l}\text { C 2014 S. Karger AG, Basel } \\
\text { www.karger.com/crg }\end{array}$ \\
\hline
\end{tabular}

Grover et al.: Hepatogastric Fistula following Transcatheter Arterial

Chemoembolization of Hepatocellular Carcinoma

\section{Disclosure Statement}

The authors have nothing to disclose.

\section{References}

1 Parkin DM, Bray F, Ferlay J, Pisani P: Global cancer statistics. 2002. CA Cancer J Clin 2005;55:74-108

-2 Fang ZT, Wang GZ, Zhang W, Qu XD, et al: Transcatheter arterial embolization promotes liver tumor metastasis by increasing the population of circulating tumor cells. Onco Targets Ther 2013;6:1563-1572.

-3 Angle JF, Siddiqi NH, Wallace MJ, et al: Quality improvement guidelines for percutaneous transcatheter embolization. J Vasc Interv Radiol 2010;21:35.

4 Park MS, Kim KW, Yu JS, et al: Radiologic findings of gastrointestinal tract involvement in hepatocellular carcinoma. J Comput Assist Tomogr 2002;26:95-101.

5 Hari S, Osama Y, Wendell C: Massive upper gastrointestinal hemorrhage due to invasive hepatocellular carcinoma and hepato-gastric fistula. World J Gastroenterol 2013;19:7472-7475.

6 Nicoll AJ, Ireton HJ, Crotty B: Gastrointestinal bleeding from hepatocellular carcinoma invading the stomach. J Gastroenterol Hepatol 1994;9:533-535.

7 Hung HC, Huang YS, Lin CC, et al: Radiotherapy in the treatment of duodenal bleeding due to hepatocellular carcinoma invasion. J Gastroenterol Hepatol 1998;13:1143-1145.

8 Duxbury MS, Garden OJ: Giant haemangioma of the liver: observation or resection? Dig Surg 2010;27:7-11.

$\$ 9$ Mehrabi A, Kashfi A, Fonouni H, et al: Primary malignant hepatic epithelioid hemangioendothelioma: a comprehensive review of the literature with emphasis on the surgical therapy. Cancer 2006;107:21082121.

10 Llovet JM, Brú C, Bruix J: Prognosis of hepatocellular carcinoma: the BCLC staging classification. Semin Liver Dis 1999;19:329-338.

11 Chung JW, Park JH, Han JK, et al: Hepatic tumors: predisposing factors for complications of transcatheter oily chemoembolization. Radiology 1996;198:33-40.

12 Brown DB, Geschwind JF, Soulen MC, Millward SF, Sacks D: Society of Interventional Radiology position statement on chemoembolization of hepatic malignancies. J Vasc Interv Radiol 2006;17:217-223.

$\checkmark 13$ Chen LT, Chen CY, Jan CM, Wang WM, Lan TS, Hsieh MY, et al: Gastrointestinal tract involvement in hepatocellular carcinoma: clinical, radiological and endoscopic studies. Endoscopy 1990;22:118-123.

14 Hashimoto M, Watanabe G, Matsuda M, Yamamoto T, Tsutsumi K, Tsurumaru M: Case report: gastrointestinal bleeding from a hepatocellular carcinoma invading the transverse colon. J Gastroenterol Hepatol 1996;11:765-767.

15 Lin CP, Cheng JS, Lai KH, Lo GH, Hsu PI, Chan HH, et al: Gastrointestinal metastasis in hepatocellular carcinoma: radiological and endoscopic studies of 11 cases. J Gastroenterol Hepatol 2000;15:536-541.

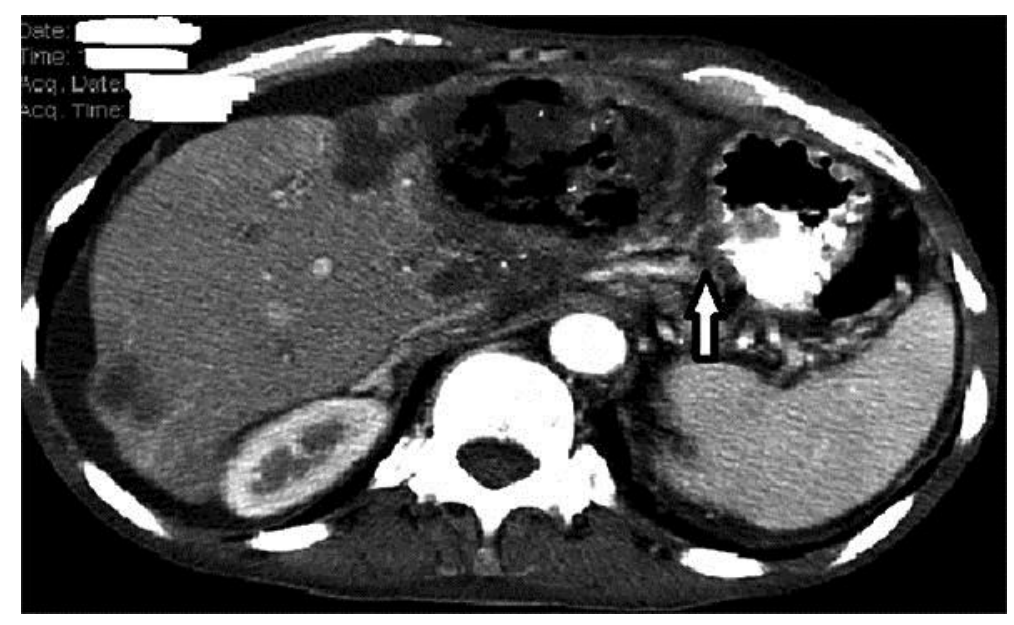

Fig. 1. Abdominal CT scan showing a fistulous connection between the lesser curvature of the stomach and the liver (arrow). 
Grover et al.: Hepatogastric Fistula following Transcatheter Arterial Chemoembolization of Hepatocellular Carcinoma

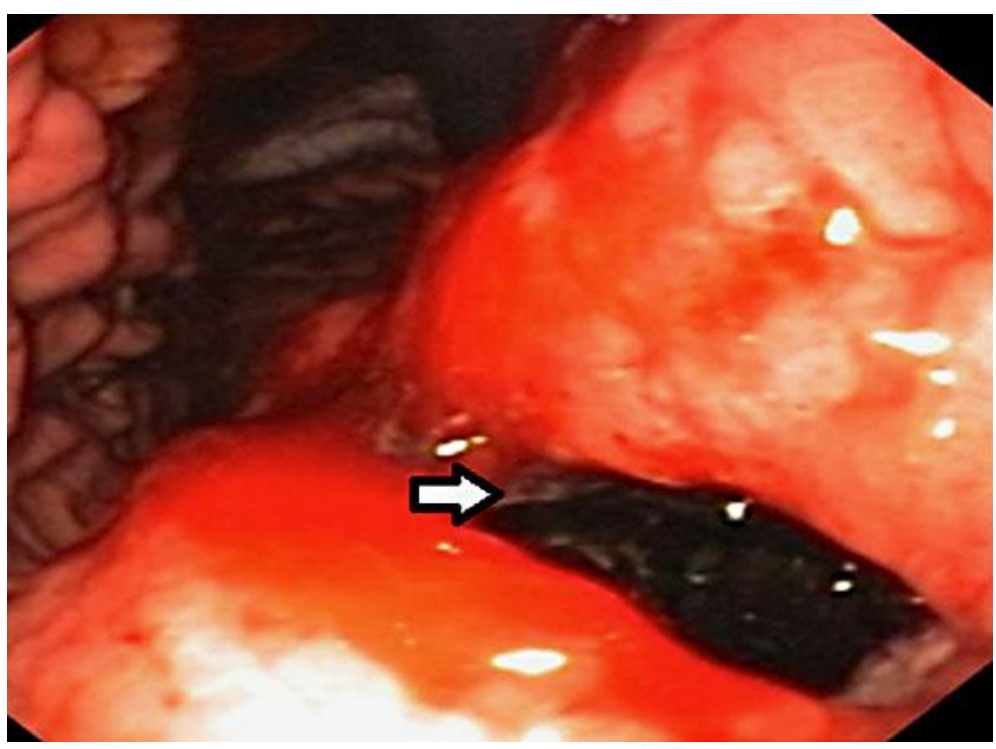

Fig. 2. Upper gastrointestinal endoscopy showing a protrusion of the tumor into the gastric lumen and the opening of a HGF (arrow). 